\title{
Ten-year survival and prognostic markers in one thousand patients with advanced heart failure. A single-centre analysis
}

\author{
Peter Lesny ${ }^{a}$, Milan Luknara, Martin Matejka ${ }^{b}$, Ivan Varga ${ }^{a}$, Peter Solik ${ }^{a}$, Sona Wimmerovac , Eva Goncalvesova ${ }^{a}$
}

\begin{abstract}
Aim. Patients with advanced heart failure (HF) represent a pool of candidates for heart transplantation and long-term mechanical circulatory support devices. The aim of our study was to determine simple and reliable markers of one-year mortality for selection of the most suitable patients for heart replacement therapy.

Methods and Results. One thousand consecutive patients with HF (mean age $49 \pm 10.9$ years; $86.8 \%$ males) referred to a single tertiary centre from January 1998 to January 2010 in order to assess the indication for heart transplantation were enrolled. Kaplan-Meier survival analysis was performed. Independent mortality predictors were established using logistic regression analysis. The mean follow-up was $4.3 \pm 2.7$ years (range 1-12 years). Cumulative survival was as follows: 1-year survival 83\%, 3-year 63\%, 5-year 50\%, 7-year 39\%, and 10-year 23\%. Independent predictors of 1-year mortality included coronary artery disease, left ventricular diastolic diameter $>79 \mathrm{~mm}$, plasma sodium $<135 \mathrm{mmol} / \mathrm{L}$, the need for intravenous treatment at hospital admission (diuretics and/or inotropes), and furosemide dose at discharge $>240 \mathrm{mg} /$ day.
\end{abstract}

Conclusions. Short-term prognosis of HF patient can be estimated based on simple parameters. Patients with signs of poor prognosis should be referred to tertiary centres to be considered for heart replacement therapy.

Key words: heart failure, survival prognosis, heart transplantation, mechanical circulatory support

Received: June 10, 2015; Accepted: September 17, 2015; Available online: October 23, 2015

http://dx.doi.org/10.5507/bp.2015.049

${ }^{a}$ Heart Failure and Transplant Department, National Cardiovascular Institute, Bratislava, Slovak Republic

${ }^{b}$ Adolescent Clinic, Dunajska Luzna, Slovak Republic

'Slovak Medical University, Bratislava, Slovak Republic

Corresponding author: Eva Goncalvesova, e-mail: eva.goncalvesova@nusch.sk

\section{INTRODUCTION}

Despite the undisputed progress in treatment, the long-term prognosis of patients with heart failure (HF) is unfavourable ${ }^{1,2}$. Patients with advanced HF represent a pool of candidates for heart replacement therapy. The number of heart transplantations (HTx) has long been stagnating due to the lack of donor organs ${ }^{3}$. In contrast, we are experiencing a significant increase in the number of implantations of mechanical circulatory support systems (MCS) (ref. $\left.{ }^{4}\right)$. It can be assumed that the use of MCS will expand further, in particular in destination therapy. From this perspective, it is of key importance to determine the prognosis of patients with advanced HF. Heart transplantation and MCS implantation are associated with non-negligible periprocedural risk, which has to be balanced against significant life extension and improvement in life quality. Currently no reliable prognostic markers are available for the selection of the most suitable heart transplant candidates.

We analysed the characteristics of patients with advanced HF, hospitalised at a single tertiary centre. Their long-term survival was evaluated. In addition, we identified independent 1-year mortality predictors. Since most patients with advanced HF are managed on an out-patient basis, we established independent 1-year mortality indicators that can be detected during an out-patient examination.

\section{PATIENTS AND METHODS}

Consecutive patients with HF referred by cardiologists to a single tertiary centre from January 1998 to January 2010 in order to assess the indication for heart transplantation were enrolled. Patients hospitalised for other reasons were not included.

During this period, 1,000 HF patients were hospitalised and monitored. There were more men (86.8\%) than women $(13.2 \%)$. Their mean age was $49.0 \pm 10.9$ years. The characteristics of patients are summarized in Table 1.

The majority of patients $(80.8 \%)$ had severe left ventricular systolic dysfunction with ejection fraction $<30 \%$; $1.8 \%$ of patients had preserved left ventricular ejection fraction ( $E F \geq 50 \%$ ).

All analysed parameters were measured during the first hospitalisation at the centre. Oral medication on discharge was evaluated. Mortality data was received from the National Health Information Centre. The day of an elective HTx was taken as the end of follow-up. HTx in urgent cases or MCS implantation was regarded as equivalent to death. MCS were implanted in our group as a bridge to transplant or to candidacy and the mean INTERMACS class at implantation was $2.1 \pm 0.6$.

\section{Statistical analysis}

Statistical analysis was performed using the SPSS statistical software, version 16.0. Nominal variables 
were characterised by arithmetic means and standard deviations. The normality of the distribution of nominal variables was tested with the Kolmogorov-Smirnov or Shapiro-Wilk tests, as appropriate. For variables with normal distribution, the parametric Student t test was used, and for variables with non-normal distribution we used the non-parametric Mann-Whitney test.

Patient survival was evaluated using the method of survival analysis, and expressed by means of Kaplan-Meier curves. In order to determine the mortality predictors, we used stepwise logistic regression analysis (backward method). Variables examined in fewer than $80 \%$ of patients and considered to have the potential to predict mortality were tested using independent mortality predictors from the previous model. The significance level for all the tests used was $P<0.05$.

\section{RESULTS}

\section{Survival Rates}

The mean follow-up was $4.3 \pm 2.7$ years (range $1-12$ years). Four hundred and sixty-nine (469) patients died during the follow-up period. One hundred and sixty-seven (167) patients underwent heart transplantation. The oneyear survival rate was $83 \%$, the 3 -year survival rate $63 \%$, the 5 -year survival rate $50 \%$, the 7 -year survival rate $39 \%$, and the 10-year survival rate $23 \%$. Survival rates are illustrated using the Kaplan-Meier curve as seen in Fig. 1.

\section{One-Year Mortality Predictors}

In order to determine independent predictors of 1-year mortality, we included 55 parameters in the multivariate logistic regression analysis. Independent predictors of one year mortality were coronary artery disease, left ventricular end-diastolic diameter (LVEDD) $>79 \mathrm{~mm}$, natraemia $<135 \mathrm{mmol} / \mathrm{L}$, need for intravenous therapy at hospital admission (diuretics and/or inotropes), and a daily dose of furosemide at discharge $>240 \mathrm{mg}$ (Table 2).

The remaining parameters examined were not significant in the multivariate analysis, although systolic blood pressure $<100 \mathrm{~mm} \mathrm{Hg}$ almost reached statistical significance $(P=0.08)$.

Some parameters of potential prognostic significance were examined in fewer patients; these were subsequently tested using the five independent predictors from the introductory model. In this manner, we tested haemodynamic parameters examined in $26.1 \%$ of patients (right atrial pressure, pulmonary artery pressures, pulmonary capillary wedge pressure, cardiac index), NT-proBNP (examined in $20.4 \%$ of patients), $\mathrm{pVO}_{2}$ (obtained during bicycle spiroergometry in $27.3 \%$ of patients), and the 6 -min walking test (performed in $75.2 \%$ of patients). In this extended analysis, the independent predictors of one-year mortality were also NTproBNP > 2,297 pg/mL, 6-min walking distance $<375$ metres, systolic pulmonary artery pressure $>60 \mathrm{~mm} \mathrm{Hg}$, and pulmonary capillary wedge pressure $>27 \mathrm{~mm} \mathrm{Hg}$ (Table 3 ).
Table 1. Patient characteristics.

\begin{tabular}{lc}
\hline Men / women (\%) & $86.8 / 13.2$ \\
Age (years) & $49.0 \pm 10.9$ \\
Systolic blood pressure (mmHg) & $118 \pm 17$ \\
Heart rate (min ${ }^{-1}$ ) & $85 \pm 17$ \\
NYHA class (patients in \%) & \\
II & 43.2 \\
III & 42.0 \\
IV & 11.6 \\
Body mass index (kg/m ${ }^{2}$ ) & $27.1 \pm 5.0$ \\
Aetiological diagnosis (patients in \%) & \\
Dilated cardiomyopathy & 57.0 \\
Coronary artery disease & 27.5 \\
Arterial hypertension & 7.1 \\
Hypertrophic cardiomyopathy & 1.6 \\
Restrictive cardiomyopathy & 1.1 \\
Other & 5.7 \\
Comorbidities (patients in \%) & \\
Arterial hypertension & 43.0 \\
Atrial fibrillation & 24.6 \\
Diabetes mellitus & 25.1 \\
CABG/PCI & 13.4 \\
Stroke & 10.5 \\
Anaemia & 17.2 \\
Renal insufficiency & 7.6 \\
Chronic obstructive pulmonary disease & 7.1 \\
NT-proBNP (median) (pg/mL) & 2,297 \\
Left ventricular ejection fraction (\%) & $24.3 \pm 7.7$ \\
Left ventricular end-diastolic diameter (mm) & $67.5 \pm 9.9$ \\
Medication (patients in \%) & \\
ACEI / ARB & 94.3 \\
Beta-blockers & 81.2 \\
Aldosterone antagonists & 63.0 \\
Furosemide & 83.6 \\
\hline
\end{tabular}

CABG - coronary artery bypass graft, PCI - percutaneous coronary intervention, ACEI - angiotensin-converting enzyme inhibitors, ARB - angiotensin II receptor blockers

\section{One-year mortality predictors available at out-patient examination}

Subsequently we focused on establishing prognostic indicators available at out-patient cardiology examination. Fifteen parameters that are generally available during a routine out-patient examination were included in the multivariate logistic regression analysis (Table 4). It was found that, of the parameters defined in this way, independent indicators of 1-year mortality include NYHA functional class III/IV, systolic BP $<100 \mathrm{~mm} \mathrm{Hg}$, coronary artery disease, LVEDD $>79 \mathrm{~mm}$, a daily furosemide dose $>240 \mathrm{mg}$, and an absence of beta-blocker (Table 5).

\section{DISCUSSION}

\section{Patient population}

Patients with advanced HF constitute a select group of patients who are considered for heart transplantation. Heart transplantation is age-limited, and this is the main 
Survival Rate

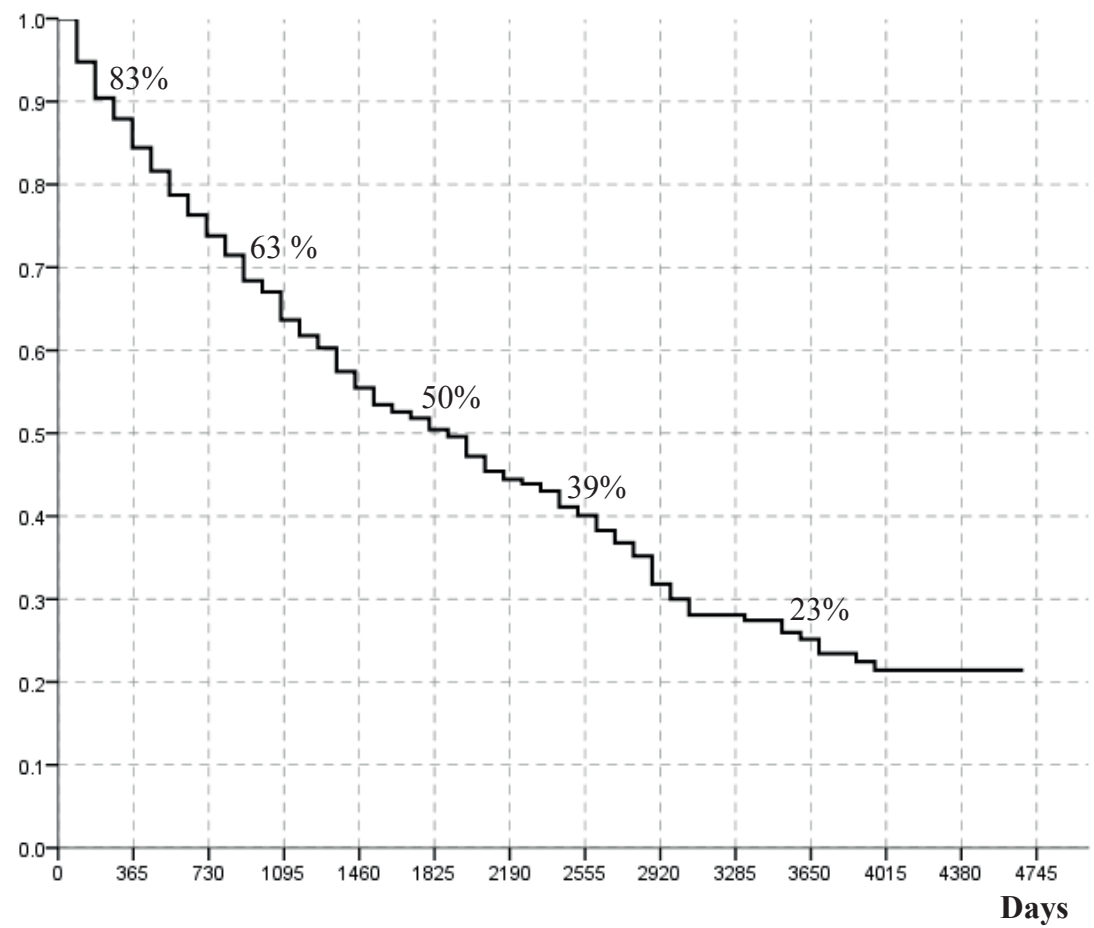

Fig. 1. Kaplan-Meier survival curve (1-year, 3-year, 5-year, 7-year, and 10-year survival are depicted).

Table 2. Independent 1-year mortality predictors.

\begin{tabular}{lcccc}
\hline Parameter & OR & $95 \% \mathrm{CI}$ & $P$ & $\begin{array}{c}\text { Number of patients } \\
\text { with the parameter (\%) }\end{array}$ \\
\hline Coronary artery disease & 2.61 & $1.51-4.51$ & 0.001 & 27.5 \\
LVEDD $>79 \mathrm{~mm}$ & 2.26 & $1.06-4.83$ & 0.035 & 9.6 \\
$\mathrm{Na}<135 \mathrm{mmol} / \mathrm{L}$ & 3.60 & $1.65-7.87$ & 0.001 & 6.8 \\
Intravenous treatment & 3.07 & $1.74-5.40$ & $<0.001$ & 21.5 \\
Daily furosemide dose $>240 \mathrm{mg}$ & 2.03 & $1.01-4.08$ & 0.048 & 11.9 \\
\hline
\end{tabular}

LVEDD - left ventricular end-diastolic diameter, OR - odds ratio, CI - confidence interval.

Table 3. Independent mortality indicators out of parameters examined in $<80 \%$ of patients.

\begin{tabular}{lcccc}
\hline Parameter & OR & $95 \%$ CI & $P$ & $\begin{array}{c}\text { Number of patients } \\
\text { with the parameter (\%) }\end{array}$ \\
\hline NT-proBNP $>2,297 \mathrm{pg} / \mathrm{mL}$ & 3.53 & $1.17-10.75$ & 0.026 & 50 \\
6-minute walking test $<375 \mathrm{~m}$ & 2.06 & $1.21-3.49$ & 0.007 & 19.4 \\
PAsys $>60 \mathrm{~mm} \mathrm{Hg}$ & 2.45 & $1.17-5.12$ & 0.017 & 20.4 \\
PCWP $>27 \mathrm{~mm} \mathrm{Hg}$ & 2.29 & $1.06-4.93$ & 0.034 & 20.0 \\
\hline
\end{tabular}

OR - odds ratio, CI - confidence interval, PAsys - pulmonary arterial systolic pressure, PCWP - pulmonary capillary wedge pressure

reason that the mean age of these patients is significantly lower than the average age of patients with $\mathrm{HF}$ in the general population ${ }^{1,5}$. At the same time, patients referred for HTx evaluation are free of significant comorbidities.

The most frequent cause of HF was DCM (57\%). The occurrence of DCM was more than double the occurrence of coronary artery disease $(27 \%)$. Other authors recorded higher incidences of coronary artery disease in a comparable population of patients ${ }^{6,7}$.
The incidence of comorbidities was relatively low. This may be because the patients were relatively young and patients with multiple comorbidities are not considered for HTx.

Diabetes mellitus with organ complications, in particular with significant nephropathy and vascular complications, is a contraindication for HTx. For this reason, the attending cardiologists often do not refer patients with significant diabetic complications to the centre for con- 
sideration for HTx. It is assumed that the thorough evaluation of renal function in HTx candidates also contributed to the relatively low occurrence of renal insufficiency in our patients. Impairment of renal functions during an episode of cardiac decompensation or during aggressive treatment with diuretics, in particular if renal function was subsequently restored, was not considered renal insufficiency. Therefore, the prevalence of renal insufficiency in our group may be regarded as occurrence of direct renal damage, e.g. in the case of diabetic nephropathy or nephrosclerosis. This is demonstrated by the difference between the occurrence of renal insufficiency (7.1\%) and hypercreatinaemia $(30.6 \%)$ in our patients. Data from US transplant centres indicate that $21 \%$ of HTx candidates have creatinaemia $>132 \mathrm{umol} / \mathrm{L}\left(\right.$ ref. $^{7}$ ). Data on the prevalence of anaemia in chronic HF with low left ventricular ejection fraction range from 4 to $61 \%\left(\right.$ ref. $^{8-10}$ ).

\section{Survival Rates}

Patients in our group had 1-year, 3-year, 5-year, 7-year and 10 year mortality of $17 \%, 37 \%, 50 \%, 61 \%$, and $77 \%$, respectively.

There is no doubt that the mortality of HF patients in the era of modern treatment has decreased, but still remains high. In the Framingham study (1948-1988), one-year and five-year mortality in cases of HF was $43 \%$ and $75 \%$ in men, and $36 \%$ and $62 \%$ in women ${ }^{11}$. Stewart et al. state that one-year and four-year mortality in $\mathrm{HF}$ patients in the period before modern treatment was $40 \%$ and $65 \%$, resp., which was worse than for most malignancies ${ }^{12}$. In comparison to the non-selected population of patients with advanced HF, the HTx candidates are younger and extracardiac comorbidities are rarer and less severe. Lietz and Miller analysed mortality on HTx waiting lists in individual periods, and concluded that mortality had decreased. In 2000-2005, compared to 1990-1994, the one-year mortality in outpatient HTx candidates on waiting lists dropped from $18.2 \%$ to $10.6 \%$. The one-year mortality of urgent HTx candidates also decreased signifi-

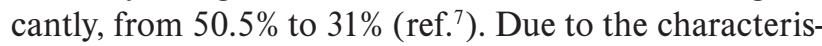
tics of our group, the mortality in our group of patients corresponds to that of patients with advanced HF with severe left ventricular dysfunction, only minimally modified by comorbidities. In this type of patient population, only $7 \%$ of patients die from non-cardiac causes ${ }^{13}$.

The 1-year mortality of HF patients hospitalised at our centre from 1998 to 2010 was $17 \%$. One-year mortality following heart transplantation was $8 \%$, and $28 \%$ following left ventricular mechanic support implantation (unpublished data). Therefore, the interventions are intended for patients in whom the risk level is balanced by appropriate benefit.

\section{One-Year Mortality Predictors}

Independent predictors of one-year mortality were coronary artery disease, left ventricular end-diastolic diameter $>79 \mathrm{~mm}$, natraemia $<135 \mathrm{mmol} / \mathrm{L}$, a daily furosemide dose at discharge $>240 \mathrm{mg}$, and the need for intravenous diuretic and/or inotrope therapy following admission. According to the statistical results, it seems
Table 4. Parameters available at outpatient examination and included in multivariate logistic regression as potential indicators of one-year mortality.

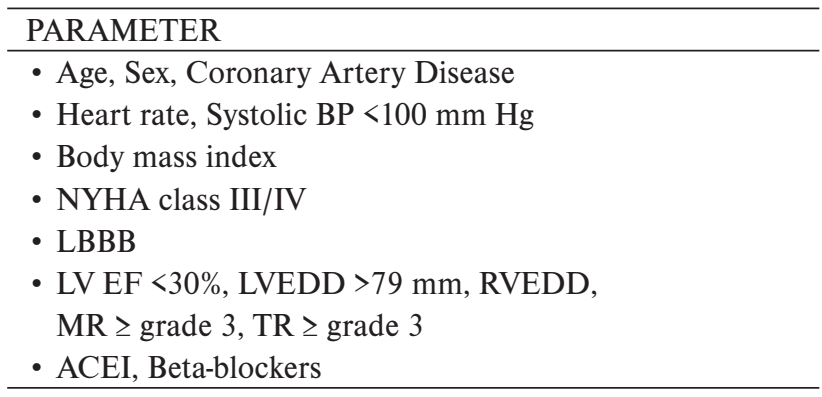

BP - blood pressure, LBBB - complete left bundle branch block, LV EF - left ventricular ejection fraction, LVEDD - left ventricular end diastolic diameter, RVEDD - right ventricular end diastolic diameter, MR - mitral regurgitation, TR - tricuspid regurgitation, ACEI - angiotensinconverting enzyme inhibitors.

Table 5. Independent 1-year mortality indicators from parameters examined at outpatient examination.

\begin{tabular}{lccc}
\hline PARAMETER & OR & $95 \% \mathrm{CI}$ & $P$ \\
\hline Coronary artery disease & 1.98 & $1.21-3.22$ & 0.006 \\
NYHA III/IV & 2.39 & $1.37-4.20$ & 0.002 \\
Sys BP < 100 mmHg & 2.34 & $1.22-4.46$ & 0.01 \\
Beta-blocker & 1.84 & $1.00-3.39$ & 0.05 \\
Daily furosemide dose $>$ 240mg & 2.40 & $1.32-4.37$ & 0.004 \\
LVEDD $>79 \mathrm{~mm}$ & 2.08 & $1.02-4.22$ & 0.043 \\
\hline
\end{tabular}

OR - odds ratio, CI - confidence interval, sys BP - systolic blood pressure, LVEDD - left ventricular end-diastolic diameter.

that the most powerful indicators of 1-year mortality in our group are hyponatraemia and intravenous therapy. Hyponatraemia is generally considered a predictor of non-favourable prognosis in HF patients ${ }^{14-18}$. Intravenous therapy comprised the administration of diuretic agents and/or inotropy. It was administered to patients with decompensated HF, or to those with signs of hypoperfusion. Significant left ventricular dilatation indicated an unfavourable development. Some authors mention the predictive value of end-diastolic ${ }^{19}$ or end-systolic left ventricular dilatation $^{20,21}$. In patients with advanced HF, it is usually necessary to administer furosemide to decrease the risk of repeated cardiac decompensation. Other predictors of one-year mortality, independent of those mentioned above, were NT-proBNP > 2,297 pg/mL, 6-minute walking distance $<375$ metres, systolic pressure in pulmonary artery $>60 \mathrm{~mm} \mathrm{Hg}$, and pulmonary artery wedge pressure $>27 \mathrm{~mm} \mathrm{Hg}$.

In the course of the follow-up period, we proceeded from BNP measurements to NT-proBNP measurements. In our group, the median NT-proBNP was $2,297 \mathrm{pg} / \mathrm{mL}$. Some authors mention the NTproBNP value of $1,000 \mathrm{pg} /$ $\mathrm{mL}$ as a limit which predicts an increased risk of adverse episodes, independent of other subjective or objective parameters $^{22}$. In the population of HTx candidates, other authors mention NT-proBNP $>4,302 \mathrm{pg} / \mathrm{mL}$ as a negative predictor ${ }^{6}$. Published data on the prognostic value 
of the 6-minute walking test in HF patients is inconsistent ${ }^{23,24}$. The walking test was not performed in patients in poor functional condition with an obvious intolerance of physical activity. The right-sided heart catheterization procedure is not a routine examination in patients with advanced $\mathrm{HF}$, but is necessary prior to inclusion on the HTx waiting list.

In general, systemic hypotension is considered a negative prognostic predictor in patients with $\mathrm{HF}^{14,15}$. In our group, systolic blood pressure $<100 \mathrm{~mm} \mathrm{Hg}$ showed a trend to increased one-year mortality, however this just failed to reach statistical significance $(P=0.08)$. Low blood pressure in this population of patients may be a sign of poor circulation. On the other hand, in stable patients, a well tolerated vasodilator treatment may contribute to a relatively lower blood pressure.

In order to increase the efficiency of the consultation process for external cardiologists with candidates for heart transplantation, we assessed 15 parameters that are easily available during a routine outpatient cardiology examination. Independent predictors of 1-year mortality that were close to significant included NYHA functional class III/IV, systolic BP $<100 \mathrm{~mm} \mathrm{Hg}$, coronary artery disease, LVEDD $>79 \mathrm{~mm}$, a daily furosemide dose $>240$ $\mathrm{mg}$, and the absence of a beta-blocker. Just as in the case of "the large" analysis, the 1-year mortality indicators were coronary artery disease, a daily furosemide dose $>240 \mathrm{mg}$ and LVEDD > $79 \mathrm{~mm}$, and also systolic BP <100 mm Hg, and absence of beta-blockers.

\section{Limitations}

Our study is a retrospective analysis. For this reason, several evaluated parameters were not available in all patients. We have been examining NT-proBNP as part of routine practice since 2007; before that we measured BNP. Since 2001, we have initiated a routine performance of the 6-min walking test in accordance with a standard protocol. In addition, some of the indication criteria changed during the follow-up period, e.g. those for the use of resynchronisation therapy. Internal manuals and procedures in our centre have also been modified and developed. Since 2007, we have experienced roughly a twofold increase in the number of heart transplantations, and implantations of mechanical support systems have started - which also influenced the HTx indication criteria.

\section{CONCLUSION}

The study describes the long-term follow-up of a selected group of patients with advanced heart failure at a single centre; their mortality is only minimally limited by paracardiac morbidity. The medium and long-term outlook for survival in this population of patients is poor. Due to the enormous increase in the number of MCS implantations and the stagnation in the number of heart transplants, the analysed patients are potential candidates for MCS implantation. Knowledge of easily available prognostic predictors may improve the identification of patients who may benefit from heart replacement therapy.
Author contributions: PL, EG: manuscript writing; PL, EG: study design; PL, ML, MM, IV, PS: data collection and analysis; PL, EG, SW: data interpretation; SW: statistical analysis.

Conflict of interest statement: The authors declare there are no conflicts of interest regarding the publication of this article.

\section{REFERENCES}

1. McMurray JJ, Adamopoulos S, Anker SD, Auricchio A, Böhm M, Dickstein K, Falk V, Filippatos G, Fonseca C, Gomez-Sanchez MA, Jaarsma T, Køber L, Lip GY, Maggioni AP, Parkhomenko A, Pieske BM, Popescu BA, Rønnevik PK, Rutten FH, Schwitter J, Seferovic P, Stepinska J, Trindade PT, Voors AA, Zannad F, Zeiher A; ESC Committee for Practice Guidelines. ESC Guidelines for the diagnosis and treatment of acute and chronic heart failure 2012: The Task Force for the Diagnosis and Treatment of Acute and Chronic Heart Failure 2012 of the European Society of Cardiology. Developed in collaboration with the Heart Failure Association (HFA) of the ESC. Eur Heart J 2012;33:1787-847.

2. Jhund PS, Macintyre K, Simpson CR, Lewsey JD, Stewart S, Redpath A, Chalmers JW, Capewell S, McMurray JJ. Long-term trends in the first hospitalization for heart failure and subsequent survival between 1986 and 2003: a population study of 5.1 million people. Circulation 2009;119:515-23.

3. Stehlik J, Edwards LB, Kucheryavaya AY, Benden C, Christie JD, Dipchand Al, Dobbels F, Kirk R, Rahmel AO, Hertz MI; International Society of Heart and Lung Transplantation. The Registry of the International Society for Heart and Lung Transplantation: 29th official adult heart transplant report - 2012. J Heart Lung Transplant 2012;31:1052-64

4. Kirklin JK, Naftel DC, Kormos RL, Stevenson LW, Pagani FD, Miller MA Timothy Baldwin J, Young JB. Fifth INTERMACS annual report: Risk factor analysis from more than 6,000 mechanical circulatory support patients. J Heart Lung Transplant 2013;32:141-56.

5. Goncalvesova E, Varga I, Lesny P, Liska B, Luknar M, Solik P. Characteristics and prognosis of patients with acute heart failure in current clinical practice. Vnitr Lek 2010;56:845-53.

6. Korewicki J, Leszek P, Zielinski T, Rywik T, Piotrowski W, Kurjata P Kozar-Kamińska K, Kodziszewska K; Polkard-Hf. Severe chronic heart failure in patients considered for heart transplantation in Poland. Cardiol J 2012;19:36-44.

7. Lietz K, Miller LW. Improved survival of patients with end-stage heart failure listed for heart transplantation: analysis of organ procurement and transplantation network/U.S. United Network of Organ Sharing data, 1990 to 2005. J Am Coll Cardiol 2007;50:1282-90.

8. Tang YD, Katz SD. The prevalence of anemia in chronic heart failure and its impact on the clinical outcomes. Heart Fail Rev 2008;13:38792.

9. Groenveld HF, Januzzi JL, Damman K, van Wijngaarden J, Hillege HL, van Veldhuisen DJ, van der Meer P. Anemia and mortality in heart failure patients a systematic review and meta-analysis. J Am Coll Cardiol 2008;52:818-27.

10. Go AS, Yang J, Ackerson LM, Lepper K, Robbins S, Massie BM, Shlipak MG. Haemoglobin level, chronic kidney disease, and the risks of death and hospitalization in adults with chronic heart failure: the Anemia in Chronic Heart Failure: Outcomes and Resource Utilization (ANCHOR) Study. Circulation 2006;113:2713-23.

11. Ho KK, Pinsky JL, Kannel WB, Levy D. The epidemiology of heart failure: the Framingham study. J Am Coll Cardiol 1993;22(4Suppl A):6A-13A.

12. Stewart S, Maclntyre K, Hole DJ, Capewell S., McMurray JJ. More malignant than cancer? Five-year survival following a first administration for heart failure. Eur J Heart Fail 2001;3:315-22.

13. Lesny $P$, Luknar M, Varga I, Solik P, Wimmerova S, Goncalvesova E. Long-term survival and prognostic markers in 1000 patients with advanced heart failure. A single-centre analysis. J Heart Lung Transplant 2013;32(Suppl):S167.

14. Yancy CW, Lopatin M, Stevenson LW, DeMarco T, Fonarow GC. ADHERE Scientific Advisory Committee and Investigators. Clinical 
presentation, management, and in-hospital outcomes of patients admitted with acute decompensated heart failure with preserved systolic function: a report from the Acute Decompensated Heart Failure National Registry (ADHERE) Database. J Am Coll Cardiol 2006;47:76-84.

15. Levy WC, Mozaffarian D, Linker DT, Sutradhar SC, Anker SD, Cropp $A B$, Anand I, Maggioni A, Burton P, Sullivan MD, Pitt B, Poole-Wilson PA, Mann DL, Packer M. The Seattle Heart Failure Model: prediction of survival in heart failure. Circulation 2006;113:1424-33.

16. Felker GM, Leimberger JD, Califf RM, Cuffe MS, Massie BM, Adams KF Jr, Gheorghiade M, O'Connor CM. Risk stratification after hospitalization for decompensated heart failure. J Card Fail 2004;10:460-6.

17. Vazquez R, Bayes-Genis A, Cygankiewicz I, Pascual-Figal D, GrigorianShamagian L, Pavon R, Gonzalez-Juanatey JR, Cubero JM, Pastor L, Ordonez-Llanos J, Cinca J, de Luna AB; MUSIC Investigators. The MUSIC risk score: a simple method for predicting mortality in ambulatory patients with chronic heart failure. Eur Heart J 2009;30:108896.

18. Binanay C, Califf RM, Hasselblad V, O'Connor CM, Shah MR, Sopko G, Stevenson LW, Francis GS, Leier CV, Miller LW; ESCAPE Investigators and ESCAPE Study Coordinators. Evaluation Study of Congestive Heart Failure and Pulmonary Artery Catheterization Effectiveness: the ESCAPE trial. JAMA 2005;294:1625-33.
19. Brophy JM, Deslauriers G, Rouleau JL. Long-term prognosis of patients presenting to the emergency room with decompensated congestive heart failure. Can J Cardiol 1994;10:543-7.

20. Bajraktari G, Emini M, Shabani X, Berisha V, Selmani H, Rexhepaj N Elezi S, Ndrepepa G. Predictors of mortality in medically treated patients with congestive heart failure of non-rheumatic etiology and reduced systolic function. Eur J Intern Med 2009;20:362-5.

21. Agha SA, Kalogeropoulos AP, Shih J, Georgiopoulou VV, Giamouzis G, Anarado P, Mangalat D, Hussain I, Book W, Laskar S, Smith AL, Martin R, Butler J. et al. Echocardiography and risk prediction in advanced heart failure: incremental value over clinical markers. J Card Fail 2009;15:586-92

22. Kim HN, Januzzi JL, Jr. Natriuretic peptide testing in heart failure. Circulation 2011;123:2015-9.

23. Bittner V, Weiner DH, Yusuf S., Rogers WJ, Mclntyre KM, Bangdiwala SI, Kronenberg MW, Kostis JB, Kohn RM, Guillotte M, SOLVD investigartors. Prediction of mortality and morbidity with a 6-min walk test in patients with left ventricular dysfunction. JAMA 1993;270:1702-7.

24. Guazzi M, Dickstein K, Vicenzi M, Arena R. Six-minute walk test and cardiopulmonary exercise testing with chronic heart failure. A comparative analysis on clinical and prognosis insights. Circ Heart Fail 2009;2:549-55. 